\title{
Biochemical Investigation of the Protective Effect of Thiamine Pyrophosphate on Methotrexate-Induced Gastrotoxicity in Rats
}

\author{
Irfan Cinar ${ }^{1}$, Mine Gulapoglu², Halis Suleyman ${ }^{3, *}$ \\ 1Department of Pharmacology, Faculty of Medicine, Ataturk University, Erzurum, TURKEY. \\ ${ }^{2}$ Department of Biochemistry, Faculty of Pharmacy, Ataturk University, Erzurum, TURKEY. \\ ${ }^{3}$ Department of Pharmacology, Faculty of Medicine, Erzincan Binali Yıldırım, Erzincan, TURKEY.
}

\begin{abstract}
Aim: The aim of the study is to investigate the protective effect of thiamine pyrophosphate on methotrexate- induced gastrotoxicity biochemically in rats and to compare it with thiamine. Methods: Rats were divided into four groups as sham (SG), thiamine + methotrexate (TAMTX), thiamine pyrophosphate + methotrexate (TPMTX) and Methotrexate (MTX) groups. $5 \mathrm{mg} / \mathrm{kg}$ methotrexate was administrated to $24 \mathrm{hr}$ fasted rat groups by oral gastric tube except sham rats. $20 \mathrm{mg} / \mathrm{kg}$ thiamine was injected to TAMTX group and $20 \mathrm{mg} / \mathrm{kg}$ thiamine pyrophosphate was injected to TPMTX group i.p. $5 \mathrm{~min}$ before the methotrexate administration. Equal amount distilled water was injected i.p. to SG and MTX groups. $6 \mathrm{hr}$ after the methotrexate administration, the rats were sacrificed with high dose thiopental anesthesia $(50 \mathrm{mg} / \mathrm{kg})$. The stomachs of the rats were extracted and MDA, MPO, GSH and SOD analyzes were performed. Results: Biochemical results were evaluated by comparing among groups. While tGSH and MDA levels and MPO and SOD activities were 4.2 $\pm 0.6,10.0 \pm 0.9,7.4 \pm 0.8$, $5.2 \pm 0.9 \mu \mathrm{mol} / \mathrm{g}$ in MTX group, these parameters were $11.0 \pm 1.0,3.4 \pm 0.4,3.3 \pm 0.5$, $13.2 \pm 1.1 \mu \mathrm{mol} / \mathrm{g}$ in SG group in the gastric tissue. These parameters were measured as $4.8 \pm 0.8,8.7 \pm 0.8,5.9 \pm 0.5,6.1 \pm 0.8 \mu \mathrm{mol} / \mathrm{g}$ in TAMTX group and $10.8 \pm 0.8$, $4.0 \pm 0.5,3.6 \pm 0.4,10.5 \pm 0.9 \mu \mathrm{mol} / \mathrm{g}$ in TPMTX group. Conclusion: The results showed that thiamine pyrophosphate prevented methotrexate induced oxidative damage in the gastric tissue, but thiamine could not prevent.
\end{abstract}

Key words: Gastrotoxicity, Methotrexate, Thiamine, Thiamin pyrophosphate, Ulcer.

\section{INTRODUCTION}

Methotrexate is an analogue of folic acid and it is used commonly either as a chemotherapeutic agent at various cancer types or at some inflammatory diseases such as psoriasis, dermatomyositis, sarcoidosis and rheumatoid arthritis. ${ }^{1}$ But serious side effects can be seen by the use of methotrexate., ${ }^{2,3}$ It was reported that the tissues which have rapidly divided cells such as gastrointestinal tract were significantly affected from methotrexate. ${ }^{4}$ Mucosal cell structure changes caused by methotrexate make gastrointestinal side effects like vomiting and diarrhea. For that reason, side effects especially gastric toxicity seen during the methotrexate treatment is the most important cause of the refuse of the therapy. Jahovic et al. showed that there has been a decrease in Glutathione levels (GSH) known as endogenous antioxidant and a significant increase in the levels of Malondialdehyde (MDA) and Myeloperoxidase (MPO) activity that is the indicator of inflammatory response in blood, liver, kidney, small bowel and stomach tissue in a single dose of $20 \mathrm{mg} / \mathrm{kg}$ methotrexate administered rats. ${ }^{5}$ Literature information suggests that antioxidant therapy may be useful in preventing and reducing the toxic effects of methotrexate on the stomach. In this study we tried to
Submission Date: 02-09-2019; Revision Date: 11-11-2019; Accepted Date: 08-01-2020

DOI: 10.5530/ijper.54.2.45 Correspondence: Dr. Halis Suleyman, Department of Pharmacology, Faculty of Medicine, Erzincan Binali Yıldırım, Kampüsü-25030, Erzincan, TURKEY

Phone: +90-0464-2123429 E-mail: halis.suleyman@ gmail.com

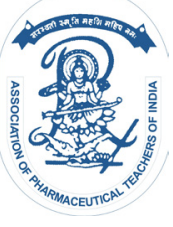

www.ijper.org 
prevent the gastric toxicity of methotrexate by using thiamine pyrophosphate which is the active metabolite of thiamine. Thiamine pyrophosphate is formed by phosphorylation of thiamine in the liver with pyrophosphokinase. ${ }^{6}$ Thiamine, although known to have antioxidant properties, ${ }^{7}$ couldn't prevent the oxidative damage generated by the ischemia-reperfusion injury in rat ovaries, however thiamine pyrophosphate was found to prevent it. ${ }^{8}$

At a scan of literature any research for the prevention of gastric damage due to methotrexate by thiamine pyrophosphate couldn't be found. Therefore, the aim of our study is to investigate the effect of thiamine pyrophosphate on the oxidative damage made by methotrexate in rat stomach biochemically and compare it with thiamine.

\section{Experimental}

\section{Experimental Animals}

In this study, a total of 24 Albino Wistar male rats weights ranging from 200-210 g were used. Animals were obtained from Ataturk University Medical Experimental Research and Application Center. Prior to the experiment, the animals were kept and fed at normal room temperature $\left(22^{\circ} \mathrm{C}\right)$ for one week (7 days) in the Department of Pharmacology, Laboratory of Ataturk University Medical Faculty in groups. Our studies being concordant to ethical rules of all stages was approved by the document of Ataturk University Local Ethics Committee for Animal Experiments (AUHADYEK) No:B.30.2.AT2A.0.23.85-86 dated 5.08.2011 and by the document of Ataturk University, Management of the Institute of Health Sciences Ethics Committee B.30.2.AT. 0.A1.00 / 00/1968 dated 30.6.2011.

\section{Thiamine pyrophosphate and thiamine's effects on gastric damage created by methotrexate}

In this study, a total of 24 albino Wistar rats were used including 6 in each group. Rats were divided into 4 groups, including Methotrexate alone (MTX), thiamine pyrophosphate + methotrexate (MTX TB), thiamine + methotrexate (TAMTX) and sham (SG) groups. Rats were fasted for $24 \mathrm{hr}$, thiamine pyrophosphate $20 \mathrm{mg} / \mathrm{kg}$ to TPMTX group and thiamine $20 \mathrm{mg} / \mathrm{kg}$ to TAMTX group were injected intraperitoneally. Equal volume of distilled water was applied in the same way to MTX group and SG. Five minutes later, methotrexate $5 \mathrm{mg} / \mathrm{kg}$ was given orally by gavage to all groups (except SG). Six hours after administration of methotrexate, the rats were sacrified by high doses of anesthesia (sodium thiopental $50 \mathrm{mg} / \mathrm{kg}$ ). After removing the stomach and evaluating the gastric surface macroscopically of all animals, all stomachs were sent to the Department of Biochemistry Laboratory, at Faculty of Medicine for the measurement of MDA and tGSH quantities and MPO and SOD activity. Biochemical test results were evaluated by comparing groups.

\section{Biochemical analysis of the stomach tissue}

To measure enzyme activity in stomach tissue, stomach tissue homogenates were prepared. In the supernatant obtained from the homogenate tGSH, MDA quantities and SOD and MPO enzyme activities were determined by suitable methods based on the literature.

\section{Preparation of samples}

At this stage of the study, $0.2 \mathrm{~g}$ from each stomach were excised. Stomachs were homogenized in icy media by completing $2 \mathrm{~mL}$ respectively with $\mathrm{pH}=6$ potassium phosphate buffer which contains $0.5 \%$ HDTMAB $(0.5 \%$ hexadecyl trimethyl ammonium bromide) for MPO assay and with $1.15 \%$ potassium chloride solution for the determination of MDA and for other measurements $\mathrm{pH}=7.5$ phosphate buffer. They were then centrifuged at $10,000 \mathrm{rpm}$ for $15 \mathrm{~min}$ at $+4^{\circ} \mathrm{C}$. The supernatant fraction was used as the analysis sample.

\section{Malondialdehyde (MDA) Determination}

It is based on measuring spectrophotometrically the absorbance of the pink complex formed by Thiobarbituric Acid (TBA) and MDA at high temperature $\left(95^{\circ} \mathrm{C}\right)$ at a wavelength of $532 \mathrm{~nm}{ }^{9}$

\section{Determination of Myeloperoxidase (MPO) Activity}

In the determining the activity of MPO enzyme, MPO mediated oxidation reaction with $\mathrm{H}_{2} \mathrm{O}_{2}$ which includes solution of 4-amino anti pyrene / phenol as a substrate was used. ${ }^{10}$

\section{Total glutathione (tGSH) Determination}

DTNB [5.5'-dithiobis (2-nitrobenzoic acid)] in the medium is a disulfide chromogen and easily can be reduced by compounds which have sulfhydryl groups. The resultant yellow color is measured spectrophotometrically at $412 \mathrm{~nm} .{ }^{11}$

\section{The determination of superoxide dismutase (SOD) activity}

It is based on to measure of the purple coloured compound formazan absorbance at $560 \mathrm{~nm}$ which is formed by the reduction of nitro blue tetrazolium by means of $\mathrm{O}_{2}$ radicals produced by xanthine oxidase added to the reaction medium. The intensity of the reduction reactions depends on the $\mathrm{Cu} / \mathrm{Zn} \mathrm{SOD}$ enzyme activity in 
the sample. The much enzyme in the environment, the less radical $\mathrm{O}_{2} \bullet$ which reacts with NBT. Thus, the severity of the purple color of formazan gets much less. ${ }^{12}$

\section{Statistical Analysis}

The results obtained from experiments were expressed as average value \pm standard deviation " $(x \pm$ SEM $)$. Significance degree of the differences between groups was determined using one- way ANOVA test. And then Fisher's post-hoc LSD (least significant differences) was made. All statistical procedures were held in" SPSS for Windows, 18.0" statistics program and $p$ value $<0.05$ was considered significant.

\section{RESULTS}

\section{Results of MDA analysis}

Methotrexate was significantly increased the MDA concentration in gastric tissue at different rates more than thiamine pyrophosphate, thiamine and sham groups. Thiamine pyrophosphate has decreased the increased MDA by methotrexate when compared to thiamin. The difference between the amount of MDA in the gastric tissue of thiamine pyrophosphate and the sham group was not statistically significant (Table 1 , Figure 1).

\section{Results of MPO Analysis}

At the MPO activity in the gastric tissue by administering methotrexate to the stomach, a significant increase was recorded. While thiamine pyrophosphate reduces the methotrexate caused MPO activity, thiamine couldn't reduce. MPO activity difference between thiamine pyrophosphate group and the sham group were meaningless, but MPO activity difference between thiamine and the sham group was significantly important (Table 1, Figure 1).

\section{Results of tGSH analysis}

As seen from Table 2, thiamine pyrophosphate prevents GSH decrease made by methotrexate in rat gastric

Table 1: The effects of thiamine and thiamine pyrophosphate on the amount of MDA and MPO in the methotrexate administered gastric tissue of the rats.

\begin{tabular}{|c|c|c|c|c|}
\hline $\begin{array}{c}\text { Groups } \\
(\mathbf{N}=6)\end{array}$ & $\begin{array}{c}\text { MDA } \\
(\boldsymbol{\mu m o l} / \mathbf{g r} \\
\text { protein) }\end{array}$ & $\mathbf{P}$ & $\begin{array}{c}\text { MPO } \\
(\mathbf{u} / \mathbf{g r} \\
\text { protein) }\end{array}$ & $\mathbf{P}$ \\
\hline MTX & $10.0 \pm 0.9$ & - & $7.4 \pm 0.8$ & - \\
\hline TPMTX & $4.0 \pm 0.5$ & $p<0.0001$ & $3.6 \pm 0.4$ & $p<0.0001$ \\
\hline TAMTX & $8.7 \pm 0.8$ & $p>0.05$ & $5.9 \pm 0.5$ & $p>0.05$ \\
\hline SG & $3.4 \pm 0.4$ & $p<0.0001$ & $3.3 \pm 0.5$ & $p<0.0001$ \\
\hline
\end{tabular}

* Results are expressed as mean \pm standard deviation. $p<0.05$ was considered significant.

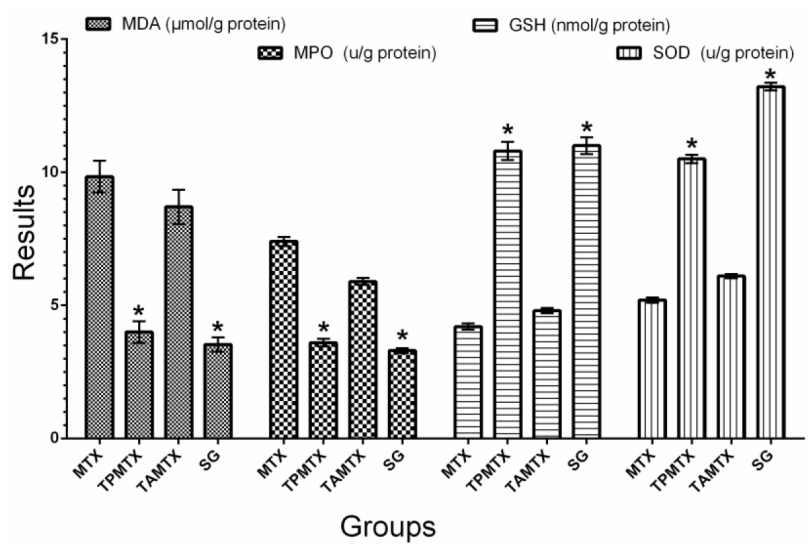

Figure 1: MDA, MPO, tGSH and SOD activity levels in rat gastric tissue in the groups MTX, TAMTX, TPMTX and SG. Results are expressed as mean \pm standard deviation and were evaluated according to the SG group. $(n=6), *$ represents the $p<0.0001$ value.

tissue and thiamine couldn't prevent. The amount of tGSH in thiamine pyrophosphate group was almost the same as the sham group, the amount of tGSH in thiamine was similar to that in the methotrexate group (Table 2, Figure 1).

\section{Results of SOD analysis}

The SOD activity in the group of rats who received thiamine pyrophosphate was found to be significantly higher compared with the group receiving methotrexate and thiamine. It was seen that thiamin was unable to prevent a decrease of SOD by methotrexate (Table 2, Figure 1).

\section{DISCUSSION}

In this study, the effects of of thiamine and thiamine pyrophosphate in the methotrexate created gastrotoxicity in rats were investigated biochemically. Test results showed that methotrexate causes significant oxidative stress in rat gastric tissue. Today, oxygen free radicals (SOR) in the development of many diseases as well as in the etiopathogenesis of methotrexate gastrotoxicity are held responsible. ${ }^{13,14}$ Antioxidant defense mechanisms in the body and SOR produced by a wide variety of events in physiological conditions are in a balance. By the deterioration of the balance against SOR, oxidative stress occurs causing tissue damage. ${ }^{15}$ Oxidative stress begins with the formation of membrane lipid radicals in the cell membrane and then this radicals converts to firstly to lipid hydroperoxides and finally the aldehyde, alkane and toxic products such as MDA. ${ }^{16}$ This may lead to changes such as ion transport disorders, changes in enzyme activity and the aggregation of cellular components. ${ }^{17}$ In other words, we meet MDA as an oxidant in the continuation and more importantly in 
Table 2: The effects of thiamine and thiamine pyrophosphate on the amount of tGSH and SOD in the methotrexate administered gastric tissue of the rats.

\begin{tabular}{|c|c|c|c|c|}
\hline $\begin{array}{c}\text { Groups } \\
(\mathbf{N = 6 )}\end{array}$ & $\begin{array}{c}\text { tGSH } \\
\text { (nmol/gr } \\
\text { protein) }\end{array}$ & $\mathbf{P}$ & $\begin{array}{c}\text { SOD } \\
\mathbf{( u / g r} \\
\mathbf{p r o t e i n )}\end{array}$ & $\mathbf{P}$ \\
\hline MTX & $4.2 \pm 0.6$ & - & $5.2 \pm 0.9$ & - \\
\hline TPMTX & $10.8 \pm 0.8$ & $p<0.0001$ & $10.5 \pm 0.9$ & $p<0.0001$ \\
\hline TAMTX & $4.8 \pm 0.8$ & $p>0.05$ & $6.1 \pm 0.8$ & $p>0.05$ \\
\hline SG & $11.0 \pm 1.0$ & $p<0.0001$ & $13.2 \pm 1.1$ & $p<0.0001$ \\
\hline
\end{tabular}

* Results are expressed as mean \pm standard deviation. $p<0.05$ was considered significant.

the exacerbating of oxidative damage. In the MTX group in our study, MDA levels were significantly increased compared to the sham group. The MDA levels in TAMTX group, compared with the MTX group, were showed no statistically significant difference. However, in TPMTX group, MDA levels were lower when compared with the MTX group and with SG group there was no statistically significant difference. These results indicate that in the gastric tissue of MTX group, oxidant / antioxidant balance is disrupted in favor of the oxidants and so, there is oxidative stress in the stomach. In the literature, studies showed that MDA increase is responsible of methotrexate related gastrotoxicity. ${ }^{18}$ Significant increase in MPO activity was observed in the gastric tissue of the methotrexate used group. While the difference between MPA activity in groups TAMTX and MTX was meaningless, the difference between groups TPMTX and MTX was significant statistically. There are many studies showing the increase of MPO activity in the damaged stomach tissue. ${ }^{19} \mathrm{PNL}$ activation causes the release of $\mathrm{O}_{2}^{-}, \mathrm{OH}^{-}$, $\mathrm{H}_{2} \mathrm{O}_{2}$ and MPO which are known as cytotoxic radicals. ${ }^{20}$ Hypochlorous acid and N-chloramines which occurs as a result of the reaction of these radicals with $\mathrm{Cl}^{-}$ and MPO initiate the cytotoxic effect in tissue. ${ }^{21}$ As it is known, to limit SOR overproduction and the damage they brought many antioxidant defense mechanisms are developed in the body. Glutathione is one of the endogenous antioxidants and protects the stomach tissue from SOR damage. GSH prevents tissue damage by providing the amount of SOR in the cells at certain concentrations and low levels. ${ }^{22}$ Decrease of GSH levels in gastric tissue makes gastric damage, increase of it creates a gastroprotective effect. ${ }^{23}$ Endogenous GSH plays an important role in maintaining gastric mucosal integrity. Reducing gastric tGSH levels by giving GSH antagonist dietilmalat to the laboratory animals, causes damage in gastric tissue, vise versa the implementation of reduced glutathione prevented the formation of gastric damage. ${ }^{24}$ This demonstrates that GSH is an important endogenous antiulcer factor. While no significant difference was observed in GSH levels in the groups of TAMTX and MTX, there was a significant increase in GSH levels in the groups of TPMTX and MTX. Also in this study, it was observed that SOD activity in gastric tissue of the MTX group was significantly lower when compared to the SG group. SOD activity of the TPMTX group was significantly increased when compared to both the TAMTX and the MTX groups. It is known that SOD activity in the injured tissues decrease. It was experimentally proven that diethylthiocarbonate which is a SOD inhibitor, inhibits the secretion of bicarbonate and this inhibition is removed by SOD. ${ }^{25}$ Our experimental results and knowledge gained from the literature reveals that SOD has gastroprotective effect and indicates that there is a direct connection between SOD and gastroprotection. In a few previously made clinical and experimental researchs thiamine and thiamine pyrophosphate were compared, in the majority of the studies, any distinction weren't made between these two substances. ${ }^{26}$ The experimental works recently done reported that, while thiamine pyrophosphate could prevent the oxidative tissue damage in ischemia reperfusion injury in the ovary, thiamine couldn't. ${ }^{8}$ These experimental results are consistent with the literature.

\section{CONCLUSION}

As a result; in the methotrexate-induced oxidative gastric damage, thiamine and thiamine pyrophosphate were found to act completely differently from each other. Thiamine pyrophosphate has created significant protective effect against methotrexate gastrotoxicity. Thiamine has remained inadequate in preventing the methotrexate gastrotoxicity. This suggests that to administer thiamine pyrophosphate which is the active form of thiamine, instead of thiamine in the methotrexate gastrotoxicity may be more appropriate.

\section{ACKNOWLEDGEMENT}

The authors are thankful to the Principal, Dr. Bahadir SULEYMAN. Faculty of Medicine, Department of Pharmacology, Erzincan Binali Yıldırım Univercity. Aurangabad for providing all the facilities required periodically for the study.

\section{CONFLICT OF INTEREST}

The authors declare that they have no conflict of interest. 


\section{REFERENCES}

1. Cetinkaya $\mathrm{A}$, et al. $\mathrm{N}$-acetylcysteine ameliorates methotrexate-induced oxidative liver damage in rats. Med Sci Monit. 2006;12(8):BR274-8.

2. Devrim E, et al. Methotrexate causes oxidative stress in rat kidney tissues. Ren Fail. 2005;27(6):771-3.

3. Hytiroglou $\mathrm{P}$, et al. The canals of hering might represent a target of methotrexate hepatic toxicity. American Journal of Clinical Pathology. 2004;121(3):324-9.

4. Jolivet $\mathrm{J}$, et al. The pharmacology and clinical use of methotrexate. $\mathrm{N}$ Engl J Med. 1983;309(18):1094-104.

5. Jahovic $\mathrm{N}$, et al. Amelioration of methotrexate-induced enteritis by melatonin in rats. Cell Biochem Funct. 2004;22(3):169-78.

6. Rindi G, et al. Further studies on erythrocyte thiamin transport and phosphorylation in seven patients with thiamin-responsive megaloblastic anaemia. J Inherit Metab Dis. 1994;17(6):667-77.

7. Bomser J, et al. In vitro anticancer activity of fruit extracts from Vaccinium species. Planta Med. 1996;62(3):212-6.

8. Demiryilmaz I, et al. A comparative investigation of biochemical and histopathological effects of thiamine and thiamine pyrophosphate on ischemia-reperfusion induced oxidative damage in rat ovarian tissue. Arch Pharm Res. 2013;36(9):1133-9.

9. Ohkawa HN, Ohishi KY. Assay for lipid peroxides in animal tissues by thiobarbituric acid reaction. Anal Biochem. 1979;95(2):351-8.

10. Bradley PP, et al. Measurement of cutaneous inflammation: Estimation of neutrophil content with an enzyme marker. J Invest Dermatol. 1982;78(3):206-9.

11. Sedlak J, Lindsay RH. Estimation of total, protein-bound and nonprotein sulfhydryl groups in tissue with Ellman's reagent. Anal Biochem. 1968;25(1):192-205.

12. Sun Y, Oberley LW, Li Y. A simple method for clinical assay of superoxide dismutase. Clin Chem. 1988;34(3):497-500.

13. Kim $\mathrm{YH}$, et al. Cardioprotective effects of rosuvastatin and carvedilol on delayed cardiotoxicity of doxorubicin in rats. Toxicol Mech Methods. 2012;22(6):488-98.
14. Momin FN, et al. Cardioprotective effect of methanolic extract of Ixora coccinea Linn. leaves on doxorubicin-induced cardiac toxicity in rats. Indian J Pharmacol. 2012;44(2):178-83.

15. Kisaoglu A, et al. Tissue Damage and Oxidant/Antioxidant Balance. EAJM. 2013;45(1):47-9.

16. Naito $\mathrm{Y}$, et al. Role of oxygen radical and lipid peroxidation in indomethacininduced gastric mucosal injury. Dig Dis Sci. 1998;43(9 Suppl):30S-4S.

17. Southorn PA, Powis G. Free radicals in medicine. I. Chemical nature and biologic reactions. Mayo Clin Proc. 1988;63(4):381-9.

18. Yapca OE, et al. The effect of mirtazapine on methotrexate-induced oxidative damage and infertility in rats. Scienceasia. 2014;40(2):152-6.

19. Zinkievich JM, et al. Gastric acid is the key modulator in the pathogenesis of non-steroidal anti-inflammatory drug-induced ulceration in rats. Clinical Experimental Pharmacology Physiology. 2010;37(7):654-61.

20. Suzuki $M$, et al. Omeprazole attenuates oxygen-derived free radical production from human neutrophils. Free Radic Biol Med. 1996;21(5):727-31.

21. Karmeli FE, Okon DR. Sulphydryl blocker induced gastric damage is ameliorated by scavenging of free radicals. Gut. 1996;38(6):826-31.

22. Ajaikumar KB, et al. The inhibition of gastric mucosal injury by Punicagranatum $L$. (pomegranate) methanolic extract. J Ethnopharmacol. 2005;96(1-2):171-6.

23. Robert A, Eberle DK. Role of glutathione in gastric mucosal cytoprotection. Am J Physiol. 1984;247(3 Pt 1):G296-304.

24. Naito $\mathrm{Y}$, et al. Role of oxygen radicals in indomethacin-induced gastric mucosal microvascular injury in rats. J Clin Gastroenterol. 1993;17 (Suppl 1):S99-103.

25. Takeuchi K, Takehara K, Ohuchi T. Diethyldithiocarbamate, a superoxide dismutase inhibitor, reduces indomethacin-induced gastric lesions in rats. Digestion. 1996;57(3):201-9.

26. Hardig L, et al. Reduced thiamine phosphate, but not thiamine diphosphate, in erythrocytes in elderly patients with congestive heart failure treated with furosemide. J Intern Med. 2000;247(5):597-600.

\section{PICTORIAL ABSTRACT}

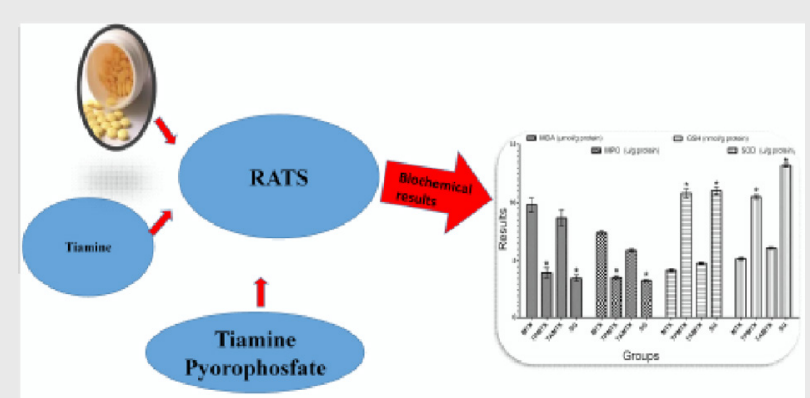

\section{SUMMARY}

The current research work shows that the effects of of thiamine and thiamine pyrophosphate in the methotrexate created gastrotoxicity in rats were investigated biochemically. Methotrexate causes significant oxidative stress in rat gastric tissue. As a result; in the methotrexate-induced oxidative gastric damage, thiamine and thiamine pyrophosphate were found to act completely differently from each other. Thiamine pyrophosphate has created significant protective effect against methotrexate gastrotoxicity. Thiamine has remained inadequate in preventing the methotrexate gastrotoxicity. This suggests that to administer thiamine pyrophosphate which is the active form of thiamine, instead of thiamine in the methotrexate gastrotoxicity may be more appropriate. 


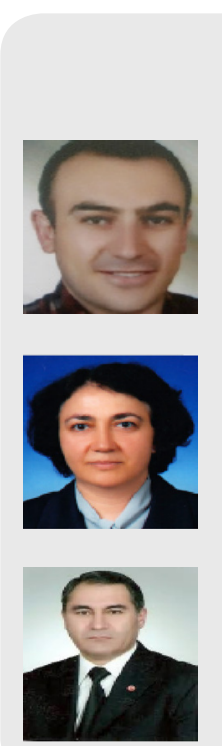

\section{About Authors}

Cinar Irfan, working as Assistant Professor, Department of Pharmacology, Faculty of Medicine Kafkas Univercity Kars, TURKEY. He has 59 citations and $3 h$-index to his credit. He has a core competency in the pharmacology.

Gulapoglu Mine, working as Professor, Department of Biochemistry Faculty of Pharmacy Atatürk Univercity Erzurum, TURKEY. She has 300 citations and $10 h$-index to her credit. She has a core competency in the extraction of herbal drugs.

Suleyman Halis, working as Professor, Department of Pharmacology, Faculty of Medicine Erzincan Binali Yildirim Univercity, Erzincan, TURKEY. He has 3250 citations and $31 h$-index to his credit. He has a core competency in the pharmacology.

Cite this article: Cinar I, Gulapoglu M, Suleyman H. Biochemical Investigation of the Protective Effect of Thiamine Pyrophosphate on Methotrexate-Induced Gastrotoxicity in Rats. Indian J of Pharmaceutical Education and Research. 2020;54(2):397-402. 